\title{
On the Origin, Development and Prospect of Rural Tourism in China
}

\author{
Zibiao Cheng1, Chengduan Wang'2, Aili Pu ${ }^{3}$ \\ ${ }^{1}$ School of Finance and Economics Management, Sichuan University of Arts and Science, Dazhou, China \\ ${ }^{2}$ Party Committee Office, Sichuan University of Arts and Science, Dazhou, China \\ ${ }^{3}$ Chengdu Neusoft University, Chengdu, China \\ Email: 47872614@qq.com
}

How to cite this paper: Cheng, Z.B. Wang, C.D. and Pu, A.L. (2018) On the Origin, Development and Prospect of Rural Tourism in China. American Journal of Industrial and Business Management, $\mathbf{8}$, 2421-2427.

https://doi.org/10.4236/ajibm.2018.812162

Received: December 10, 2018

Accepted: December 26, 2018

Published: December 29, 2018

Copyright $\odot 2018$ by author(s) and Scientific Research Publishing Inc. This work is licensed under the Creative Commons Attribution International License (CC BY 4.0).

http://creativecommons.org/licenses/by/4.0/

\begin{abstract}
This paper explores the origin of rural tourism in China, and holds that rural tourism in China originated from the first Litchi Festival held in Shenzhen in 1988. Through the analysis of the development history of rural tourism in China for 30 years, the development of rural tourism in China is divided into three stages, which predicts the development direction of rural tourism in China.
\end{abstract}

\section{Keywords}

China, Rural Tourism, Origin, Development, Prediction

\section{Introduction}

The Central Committee Document No. 1 of 2018 and the Strategic Plan for Vitalization of Rural Areas (2018-2022), issued by the Central Committee of the Communist Party and the State Council, made the decision to implement the leisure agriculture and rural tourism quality projects. In January of the same year, the Agricultural Products Processing Bureau of the Ministry of Agriculture and Rural Areas made the implementation of the upgrading of leisure agriculture and rural tourism as a priority in 2018 [1]. On April 13, the Ministry of Agriculture and Rural Areas issued the Notice on Promoting Leisure Agriculture and Rural Tourism, and the Notice on Promoting Leisure Agriculture and Rural Tourism by the Office of the Ministry of Agriculture and Rural Areas on July 13. The era of comprehensive transformation and upgrading of rural tourism development has come. In the critical period of the transformation and development of rural tourism in China, it is urgent to define the definition of rural tourism, explore the origin of rural tourism, grasp the development track of rural 
tourism and recognize the development trend of rural tourism, so as to promote the development of rural tourism into the new era, seize opportunities, meet challenges and take the road of transformation and development of rural tourism with Chinese characteristics.

\section{The Concept of Rural Tourism}

Xiao Youxing (2001), a domestic scholar, first studied the concept and types of rural tourism, believing that localism is an important connotation of the concept of rural tourism. He Jingming (2002) published an article entitled Discussion on the Concept of Rural Tourism in the Journal of Southwest Normal University (Humanities and Social Sciences Edition). He believed that localism was the most important symbol of defining the concept of rural tourism. He pointed out that rural tourism in a narrow sense refers to tourism activities in rural areas attract tourists with rural natural and cultural objects [2]. Until December 22, 2018, this article has been cited 912 times, ranking second in the research on rural tourism. Domestic scholars generally agree with the definition of rural tourism by He Jingming. The concept of rural tourism referred to in this paper also adopts the concept of rural tourism defined by Mr. He Jingming (2002).

\section{The Origin of Rural Tourism in China}

Rural tourism has a very long history in China, which can be traced back to the Spring and Autumn Period and the Warring States Period [3]. During that Period, the countryside was a farming place, which had been transformed many times and the basic conditions for tourism. However, the areas had not been transformed by human without conditions for tourism at all. It could be said that the "rural tourism" at that time was a choice based on objective reality. The rural tourism discussed in this paper is different from the rural tourism in the Spring and Autumn Period and the Warring States Period in terms of development motivation and mechanism. Therefore, the author set the time for the discussion of the origin of rural tourism in modern times. Cha Fang [4] (2004) concluded that the origin of rural tourism has two kinds of views. One is that it originated from Shandong Foreign Affairs reception in the 1950s, and the other is that it originated from Shenzhen Litchi Festival in the 1980s. From June 28 to July 8 in 1988, the first Litchi Festival was held in Shenzhen. 220,000 guests from home and abroad were invited to participate in the festival. Various forms of economic, trade and cultural friendship activities were carried out under the theme of "Litchi". These activities included tasting fresh litchi gardens, that is, picking them immediately and enjoying the beautiful scenery of Litchi Township [5]. The large scale, wide influence and various forms of activities conform to the connotation of the definition of rural tourism by scholars at home and abroad. Therefore, the author more agrees that domestic rural tourism originated from the first Litchi Festival held in Shenzhen in 1988. Subsequently, Ling Shen [6] (1990) published an article entitled On the Development of Rural Tourism Re- 
sources in China in Research on Agricultural Modernization, which established a concept for the development of rural tourism in China and opened up the academic research on rural tourism in China.

\section{Development of Rural Tourism in China}

On December 22, 2018, a total of 12381 results were found by searching the article titled Rural Tourism through China HowNet (http://www.cnki.net/). The results were collated, summarized and analyzed, and Figure 1 was made. According to Figure 1, the research on rural tourism by domestic scholars is combined with the development of rural tourism in China. The development of rural tourism in China is divided into three stages.

\subsection{First Stage-Budding Stage (from 1988 to 2005)}

Influenced by the first Litchi Festival in Shenzhen in 1988, rural tourism relying on agricultural products picking has been launched in various places. Rural tourism has sprouted in places with convenient transportation and beautiful scenery. At this stage, a few researchers began to pay attention to rural tourism, and the research area was relatively narrow, mainly involving the origin, concept and development of rural tourism resources. Some authors had discussed it such as Jin Xueliang [7] (1992), Shu Xianglian [8] (1997), Zhou Zuoming [9] (1999), Gao Zengwei [10] (2002), Yang Yan [11] (2003) and so on. There are few researches published at this stage. In 2005, 95 publications were published, with the largest number. In 1988, 1989, 1991 and 1995, the number was 0.

\subsection{Second Stage-High-Speed Development Stage (from 1988 to 2005)}

In 2006, the State Tourism Administration fully implemented the Outline Recommendations of the Eleventh Five-Year Plan adopted by the Fifth Plenary Session of the Sixteenth Central Committee of the Communist Party of China on October 8 , 2005. It is required to firmly promote the construction of a new socialist countryside and the tourism industry. The theme of National Tourism in

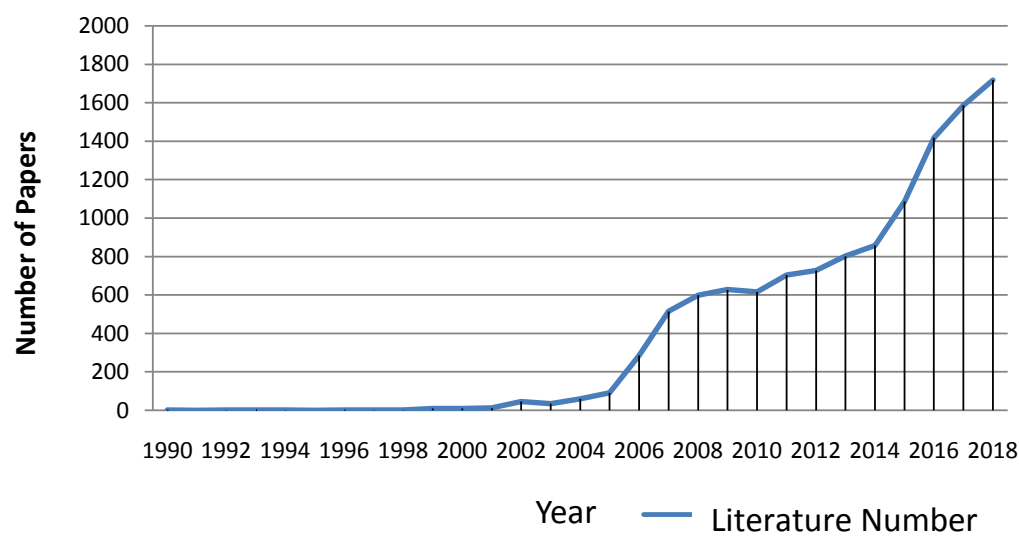

Figure 1. Time series map of domestic rural tourism literature number. 
2006 is defined as China's rural tourism in 2006, and the slogan is new countryside, new tourism, new experience, and new fashion. In 2015, document No. 1 of the Central Committee of China proposed that we should actively develop various functions of agriculture and tap the value of rural ecological leisure, tourism, culture and education. On the 5th China Tourism Day, Wang Yang, Vice Premier of the State Council investigation focused on Tourism poverty alleviation poverty area in Hubei of Enshi on May 19 of same year. He stressed that rural tourism is the creation of the grassroots and the masses, which is an effective way of poverty alleviation in poor areas, and an important channel for the poor people out of poverty. Document No. 1 of the Central Committee in 2016 stressed that leisure agriculture and rural tourism should be vigorously developed. Efforts should be made by strengthen planning guidance, rewards instead of subsidies, construction first and then subsidies, financial discounts and the establishment of industrial investment funds to support the development of leisure agriculture and rural tourism. In this stage, the country vigorously promulgated a series of policies to guide the development of rural resources, promote the rapid development of rural tourism.

Thanks to the policies and the rapid development of rural tourism, scholars have paid more and more attention to the study of rural tourism and expanded their horizons. Wang Yu [12] (2012) proposed the organic combination of Four Farmers' Home and rural tourism. Zhou Qing [13] (2015) believed that the new urbanization mainly affects the development of rural tourism by influencing the residents, communities and governments of tourist destinations. Fang Lingmei [14] (2016) thought that there is an interactive relationship between beautiful rural construction and rural tourism development. In this stage, the research results are blooming everywhere, and the number of research has been greatly increased. In 2015, the number of publicly published results exceeded 1000 for the first time, reached 1087, and in 2016, reached 1419. Although domestic scholars have carried out a comprehensive and in-depth study on rural tourism development, they have paid little attention to the quality of rural tourism development and transformation.

\subsection{Third Stage-Transitional Development Stage (from 2017 until Now)}

The second time in a row, rural tourism was clearly put forward in No. 1 document of the Central Committee in 2017. However, compared with No. 1 document of the Central Committee in 2016, it pays more attention to the development direction and path of rural tourism development. In 2018, the Central Committee Document No. 1 and the Strategic Planning for the Revitalization of Rural Areas (2018-2022), issued by the Central Committee of the Communist Party and the State Council, highlighted the implementation of leisure agriculture and rural tourism quality projects, and putting rural tourism development quality and transformation in a prominent position. Guided by the national policy, rural tourism has entered a stage of transformation, upgrading and devel- 
opment that emphasizes quality and sustainable development.

The domestic scholars focus on rural tourism is constantly rising, some scholars begin to think calmly on the next step in the development of rural tourism. In 2017, 1587 research papers were published publicly, and it is expected that more than 2000 research papers will be published in 2018. In the research results, more attention is paid to the quality of rural tourism development and transformation and upgrading. Domestic scholars are studying the field of rapid development of rural tourism and gradually transform to the quality of rural tourism development, connotation, transformation and so on.

\section{Development Prospect of Rural Tourism in China}

\subsection{Innovation and Reform Driving Development}

Due to the national policy, the rural tourism market is flourishing, and goes smoothly. However, it is difficult to conceal the phenomenon of lack of characteristics, individuality and homogeneity in the development of rural tourism, and the sustainability of rural tourism development is not guaranteed. Only by adhering to the guidance of the "five development concepts", carrying out comprehensive innovation in the development of rural tourism, retaining the original flavor of "rural" without losing its individuality and characteristics, can the development of rural tourism be guaranteed to have permanent vitality and achieve sustainable development.

\subsection{Local Industrialization of Rural Tourism}

At present, in rural tourism development areas, it is common to attach importance to the development of rural tourism resources and neglect the development of supporting industries. Poor accessibility, vulgar and single entertainment projects, simple living and poor sanitary conditions are prominent problems. Providing a situation for tourists to come, play, eat, and live and so on is a difficult problem in the transformation and upgrading of rural tourism development. The key to solve the problem lies in promoting the industrialization of rural tourism in situ and cultivating a perfect industrial chain of "travel, purchase, entertainment, eat, live and travel". Local industrialization is also a response to the industrial prosperity in the strategy of rural revitalization. It can help rural tourism development to transform and upgrade, and Rural Revitalization can drive the virtuous circle of rural tourism development to transform and upgrade.

\subsection{Cultivating Vitalized Traditional Rural Culture}

Old houses, ancient trees, bridges, streams and other traditional cultural features are the shape of traditional culture, which will not tell its own Millennium story. Understanding the cultural inheritors of it is the soul of traditional culture. For example, when the inheritors reproduce the cultural stories in a completely new way with the characteristics of the times, the traditional culture will be stereos- 
copic in the minds of tourists and live up when they look and listen to their legendary which unified the soul and form of traditional culture.

\subsection{Creating Intelligent Tourism, Individual Tourism and Experience Tourism}

In the Internet era, everything is connected by using of big data, block chains and other Internet technologies to open up rural tourism information channels. By analyzing the tourist preference data, we can simplify the rural tourism and provide the tourists with wisdom, individuality and experience of rural tourism, which meet the needs of the times and modern aesthetics.

\section{Conclusion}

After 30 years of development, China's rural tourism has entered the stage of transformation and development which began in 1988. Through innovation and reform, local industrialization of rural tourism, and cultivation of living traditional rural culture, it will be the key directions of rural tourism transformation and development by creating wisdom tourism, personality tourism and experience tourism. The transformation and development of rural tourism is a systematic project, which needs support from all aspects and levels. Therefore, it is very important to study the interaction between rural tourism transformation and development, urbanization and industrialization.

\section{Funding}

1) Sichuan Provincial Social Sciences Research High-level Research Team: Sichuan Old Revolutionary Base Areas' Ecological Civilization Construction Research Team (Project No.: 18SCTD01).

2) Subsidized by Sichuan Tourism Development Research Center, Sichuan Key Research Base of Philosophy and Social Sciences. (Project No. LYC18-47).

3) Subsidized by Sichuan Revolutionary Old Area Development Research Center 2017 Subsidy (SLQ2017C-09).

4) Subsidized by Sichuan Landscape and Recreation Research Center Project 2018 (JGYQ 2018036).

\section{Conflicts of Interest}

The authors declare no conflicts of interest regarding the publication of this paper.

\section{References}

[1] Circular of Guangdong Provincial Agricultural Department. Issue of Key Points for the Work of the Office of Agricultural Products Processing in 2018. http://zwgk.gd.gov.cn/006939908/201803/t20180306_755280.html

[2] He, J.M. and Li, L.H. (2002) On the Concept of Rural Tourism. Journal of Southwest Normal University (Humanities and Social Sciences Edition), No. 5, 127-128.

[3] He, X.R. (2001) Discussion on the Origin, Present Situation and Development 
Trend of Rural Tourism in China. Journal Beijing International Studies University, 1, 90-94.

[4] Cha, F. (2004) On the Origin and Concept of Rural Tourism. Journal of Ankang Teachers College, 6, 29-32.

[5] Promoting Regional Economic Development in Shenzhen Nanshan Litchi Cultural Tourism Festival. China United Business News. http://www.cubn.com.cn/news3/news_detail.asp?id=12779

[6] Ling, S. (1990) On the Development of Rural Tourism Resources in China. Research on Agricultural Modernization, 5, 14-17+43.

[7] Jin, X.L. and Chen, C.Y. (1992) Development and Utilization of Rural Tourism Resources. Human Geography, 3, 28.

[8] Shu, X.L. (1997) On Rural Tourism Resources and Their Development in China. Tourism Research and Practice, 2, 25-29.

[9] Zhou, Z.M. (1999) Towards a Broad Countryside: A Series of Research on Tourism Resources Development in Guangxi. Journal of Guangxi University for Nationalities, S1, 73-74+101.

[10] Gao, Z.W. and Gao, H. (2002) Characteristics, Classification and Development and Utilization of Rural Tourism Resources. Journal of Jinling Vocational University, 3, 60-64.

[11] Yang, Y. (2003) On the Development of Rural Tourism in Chongqing. Journal of Chongqing University of Industry and Commerce, 6, 114-116.

[12] Fang, L.M., Li, Y.H., Yang, F. and Ding, L.Q. (2016) Research on the Development Path of Rural Tourism around Chaohu Lake under the Background of Beautiful Rural Construction. Journal of Central South University of Forestry Science and Technology, 6, 62-67.

[13] Zhou, Q. (2015) Study on the Interaction Mechanism between Rural Tourism and New Urbanization. Journal of Taiyuan City Vocational and Technical College, 12, 17-19.

[14] Wang, Y. (2012) Rural Tourism Development Promotes New Rural Construction: A Case Study of Loushanguan Village, Banqiao Town, Huichuan District, Zunyi City. Rural Discovery in China, 4, 183-186. 